\title{
Phytopathogen resistance of phytohormone-deficient and low-sensitivity mutant tomatoes ${ }^{1}$
}

\author{
Carla Dias Tunes *(D), Vanessa Pinto Gonçalves², Daniele Brandstetter Rodrigues², Andréia da Silva Almeida², \\ Priscila Rossatto Meneses ${ }^{2}$, Alexandre Milech Neumann ${ }^{2}$
}

10.1590/0034-737X202168030007

\begin{abstract}
This study broadens the knowledge of plant-pathogen interactions using phytohormone-deficient and low-sensitivity mutant tomatoes. The experiment was performed under greenhouse conditions and the mutants used were provided by the HCPD laboratory, at ESALQ/USP. The hormone mutant Never ripe showed a larger final lesion size when inoculated with Botrytis cinerea, whereas curl3 was relatively resistant to this pathogen and more susceptible when inoculated with Phytophthora infestans. The transgenic 35S :: nahG was more susceptible to Oidium lycopersici, and the double mutant dgt, $\mathrm{Nr}$ more resistant. The low sensitivity to brassinosteroids confers greater susceptibility to $P$. infestans and higher resistance to $B$. cinerea. The deficiency of the hormone auxin promotes high resistance to diseases caused by O. lycopersici, P. infestans and B. cinerea.
\end{abstract}

Keywords: Botrytis cinerea; Oidium lycopersici; Phytophthora infestans; hormonal signaling.

\section{INTRODUCTION}

Despite the absence of an immune system similar to animals, plants have developed an impressive variety of defenses, conceived to detect invasive organisms and suppress pathogens before serious damage occurs (Freeman \& Beattie, 2008). This system coordinates, in an effective manner, the activation of specific defenses, minimizing the energy costs while the ideal resistance is reached (Pieterse \& Dicke, 2007).

The plant defense system is composed by a complex of responses that are activated after pathogen detection and have evolved over millions of years, in parallel to the evolution of pathogenicity and virulence mechanisms on phytopathogenic microorganisms (Kazan \& Lyons, 2014). The adequate regulation of these defense responses is extremely important for plants since pathogens have deleterious effects on growth (Glazebrook, 2005).

During non-host interactions, the microorganism is recognized by MAMPs (Microbial associated molecular patterns), that constitute the basal plant resistance and act against potential pathogens (Uma et al., 2011). The microorganisms that overcome this first defense barrier become pathogens which can present different types of parasitism as necrotrophic, hemi-biotrophic and biotrophic. Necrotrophic pathogens act directly on plant tissues, using an arsenal of pathogenicity and virulence factors, such as toxins and enzymes, therefore, various genes are necessary to confer host resistance (Laluk \& Mengiste, 2010). Biotrophic pathogens are more evolved parasites that require a living host for survival, using the haustorium to absorb nutrients, presenting host specificity determined by the presence of effectors, which may result on plant resistance mediated by one single resistance gene (gene R) (Jones \& Dangl, 2006). Hemi-biotrophic pathogens present a transitory relationship between biotrophic and necrotrophic. These pathogens present, on the initial phase of infection, strategies similar to those observed on biotrophic pathogens, with the use of

\footnotetext{
Submitted on June $19^{\text {th }}, 2019$ and accepted on December $13^{\text {th }}, 2020$.

${ }^{1}$ This work is part of the master's thesis of the first author.

${ }^{2}$ Universidade Federal de Pelotas, Pelotas, Rio Grande do Sul, Brasil. carladtunes@gmail.com; vanessapg83@hotmail.com; ufpelbrandstetter@hotmail.com; andreiasalmeida@yahoo.com.br; prisrossatto@ hotmail.com; alexandreneumann@hotmail.com

* Corresponding author: carladtunes@gmail.com
} 
effectors, and a second phase similar to those observed on necrotrophic pathogens, as the use of toxins (Laluk \& Mengiste, 2010).

The type of parasitism involved triggers different plant responses from the connections of the phytohormones to receptors via signal transduction pathways (Inácio et al., 2011). Phytohormones, such as salicylic acid (SA), jasmonic acid (JA) and ethylene (ET) are involved in these signaling events of defense responses. Generally, SA is involved in defense responses against biotrophic and hemi-biotrophic pathogens while JA and ET mediate the responses against necrotrophic pathogens (Bari \& Jones, 2009)

Other phytohormones, such as abscisic acid (ABA), auxin (AX), brassinosteroids (BR), and gibberellic acid (GA), which are commonly known due to their roles on stress tolerance or plant growth and development, also regulate defenses, individually or together with SA, JA and ET (Robert-Seilaniantz et al., 2011; Torres et al., 2014).

The identification and characterization of several mutants affected on phytohormone biosynthesis, perception and signal transduction has been fundamental to comprehend the role of individual components of each phytohormone on defense signaling pathways. The interaction among these signaling pathways is an important mechanism for defense response regulation against a variety of pathogens (Bari \& Jones, 2009).

Anyway, the disease as a result of host-pathogen interactions is the main limiting factor for the performance of agricultural production. In extreme cases, where important crops are affected, these interactions may result in epidemies with great losses (Pascholati et al., 2008).

Tomatoes, for example, are attacked by several phytopathogens, with more than 200 already described, as the oomycete Phytophthora infestans ((Mont) de Bary) which may make production unfeasible under some conditions. $P$. infestans causes the disease known as mela or late blight, which occurs in almost all regions where tomatoes are grown and is among the most important diseases that cause significant economic damage to the crop (Nick et al., 2013). Under controlled environment agriculture, due to the high air relative humidity, the occurrence of diseases such as the gray mold and the powdery mildew are frequent. The gray mold, caused by Botrytis cinerea (Pers.), under these conditions, is one of the main diseases that affect tomatoes, capable of causing damage on all plant parts, initiating on flower petals and progressing to the leaflets, stems and fruits (Pereira, 2015). Diseases known as powdery mildew, caused by Oidium lycopersici (Cooke \& Mass.), are also favored by controlled environments and are more common in the dry winter years, usually with lesions progressing from older leaves (Cerkauskas \& Brown, 2015).
In this context, the aim of this study was to broaden the knowledge of plant-pathogen interactions using phytohormone-deficient and low-sensitivity mutant tomatoes, to investigate hormonal relationships on plant defense pathways.

\section{MATERIAL AND METHODS}

The experiments were carried out in a greenhouse of the Phytopathology and Nematology Department at ESALQ/USP, performed under completely randomized design with six repetitions. Each experimental unit was composed of one plant and the treatments were the mutants (described below). For each pathogen (Botritys cinerea, Phytophthora infestans and Oidium lycopersici) the experiments were performed separately, totalizing three stages, one for each pathosystem, with 66 experimental units each.

The mutants used in this study were provided by the HCPD laboratory (Hormonal Control of Plant Development) at ESALQ/USP, and have the same genetic background that the parental, cultivar Micro-Tom, except the mutations. The hormone mutants used were diageotropica (dgt) - plants have low sensitivity to auxin; notabilis (not) - plants present a low concentration of abscisic acid; Never ripe ( $\mathrm{Nr}$ - - which has a low sensitivity to ethylene; epinastic (epi) - plants have an overproduction of ethylene; procera (pro) - plants present a constitutive response to gibberellins; curl3 (cu3) - plants which carry the mutant allele are insensible to brassinosteroids; and 35S::nahG - plants with reduced levels of salicylic acid. Additionally, the double mutants of dgt,pro, dgt, $\mathrm{Nr}$, and dgt,epi were used.

Seeds of each mutant were sown in $250 \mathrm{~mL}$ pots, using a mixture of organic substrate and vermiculite in a $1: 1$ ratio, and individual seedling transplant to $150 \mathrm{~mL}$ pots occurred at 15-21 days after sowing.

For the inoculations of $B$. cinerea and $P$. infestans, microdrops of $15 \mu \mathrm{L}$ of the conidial $\left(1 \times 10^{5} \mathrm{~mL}^{-1}\right)$ and sporangia $\left(1 \times 10^{5} \mathrm{~mL}^{-1}\right)$ suspensions, respectively, were applied on the surface of the three youngest leaves of each mutant, at the beginning of the reproductive stage. Immediately after inoculation, plants were held into a wet chamber for 48 hours. The inoculation with $O$. lycopersici was accomplished by sprinkling the conidial suspension $\left(2 \times 10^{4} \mathrm{~mL}^{-1}\right)$ on the whole plant at flowering using a hand sprayer, without the use of a wet chamber. After inoculated, plants were held into a refrigerated greenhouse using wet air ventilation until the moment of the evaluations, with temperatures varying between 20 to $30^{\circ} \mathrm{C}$.

The evaluations of $B$. cinerea and $P$. infestans were performed using the variables: incubation period (IP), disease incidence (DI), lesion growth rate $(r)$ and final lesion size (FLS). For P. infestans, disease severity (DS) 
was also quantified. The IP was determined by monitoring plants every 6 hours, from pathogen inoculation to the emergence of the first symptoms and was established as the average time for $50 \%$ of the plants in the treatment to express characteristic symptoms of the disease. DI was expressed as the percentage of infected and symptomatic plants at 120 hours after inoculation. The lesion growth rate $(r)$ was obtained from daily measurements of one lesion on one leave per plant during seven days after the IP, using a digital caliper; the results of the measurements were used to calculate the $r$, determining the slope of the linear model obtained by linear regression. The FLS, in millimeters, was measured at 216 hours after inoculation (hai) with the aid of a digital caliper. The severity of late blight was determined using a diagrammatic scale proposed by Corrêa et al. (2009). For $O$. lycopersici, the variables evaluated were the latent period (LP), disease incidence (DI) and the quantification of disease severity (DS). The LP (hours) was obtained by the examination of leaves every 12 hours after inoculation and was defined as the time interval from the inoculation to the presence of colonies with spores and established as the average time necessary for at least half of the plants of each treatment to have symptoms. DI was expressed as the percentage of infected and symptomatic plants at each treatment 360 hours after inoculation. At the end of the evaluations, symptomatic leaves were photographed and processed using the software QUANT to determine the DS.

Data were subjected to the analysis of variance using the $\mathrm{F}$ test $(\mathrm{p} \leq 0.05)$. When statistical significance was verified, the effects of the mutants were compared using the Tukey test $(\mathrm{p} \leq 0.05)$.

\section{RESULTS AND DISCUSSION}

For the development of the disease process, an exception rather than the rule, the infection of the plant by a pathogenic microorganism is necessary (Pascholati et al., 2008). The plant, for defense, requires adaptations to different types of attack, accordingly to the forms of parasitism of each pathogen. Whereas biotrophic organisms are completely dependent of a living host for survival, necrotrophs cause cell death releasing phytotoxic compounds or enzymes that promote cell wall degradation and the release of nutrients which are necessary for growth (Vleeshouwers \& Oliver, 2014). Hemibiotrophic microorganisms, on the other hand, stablish a transitory relationship, initially acting as biotrophs and, after infection, as necrotrophs, constituting distinct phases with variable duration within hemi-biotrophs (Laluk \& Mengiste, 2010).

Therefore, as results of the variables evaluated against these different types of parasitism, the variation in the incubation period among hormone mutants was not significant for gray mold (B. cinerea) and late blight $(P$. infestans) (Table 1). The latent period for powdery mildew (O. lycopersici) did not vary significantly among tomato mutants either, except for the mutant notabilis and dgt, $\mathrm{Nr}$ which presented a latent period $18 \%$ greater than the observed for the diageotropica mutant.

Disease incidence (DI) significantly reduced for gray mold, compared to Micro-Tom, being 50\% lower for the mutants diageotropica, procera, notailis, dgt,pro and dgt,epi (Table 2). For mutants curl3 and 35S::nahG the decrease was of 75 and $17 \%$, respectively. Late blight incidence reduced significantly, compared to Micro-Tom, wherein the DI was 50\%, 34\%, 25\%, $17 \%$ and $17 \%$ lower for $35 \mathrm{~S}:$ :nahG, diageotropica, dgt,pro, epinastic and procera, respectively. For powdery mildew the DI decreased significantly, compared to Micro-Tom, the decreases were of $20 \%$ for the mutant curl 3 and $17 \%$ for the mutants diageotropica, procera, notabilis and dgt,pro.

The final lesion size (FLS) and lesion growth rate $(r)$ did not differ statistically among mutants for late blight. On the other hand, for powdery mildew, the FLS and $r$ were $87 \%$ lower for the mutant curl3 compared to MicroTom (Table 3). The greater FLS was observed for the mutant Never ripe, which was $88 \%$ greater than the observed for curl3. The greater $r$ was observed for the mutants Never ripe and dgt,Nr, which did not differ from Micro-Tom, and were 87 and $88 \%$ greater than the observed for curl3, respectively.

Disease severity (DS) of late blight for curl3 was 65 to 93\% greater when compared to the hormone mutants diageotropica, Never ripe, epinastic, notabilis, dgt,pro, dgt, $\mathrm{Nr}$ (Table 4). DS for powdery mildew did not differ significantly for mutants compared to Micro-Tom. The mutant 35S::nahG presented the greater DS which was 90\% superior than the observed in dgt, $\mathrm{Nr}$.

In this context, the pathogen $O$. lycopersici absorbs nutrients from the host using the haustorium, which is a characteristic of typical biotrophic parasites (Dallagnol \& Araujo Filho, 2018), the resistance triggered by the plant organ against this style of parasitism is of the induced type, mediated mainly by the hormone salicylic acid (SA) (Debona \& Rodrigues, 2018). In the case of transgenic plants that express the nahG gene, as the mutant $35 \mathrm{~S}::$ nahG in tomato, the codification of the enzyme salicylate hydroxylase inactivates SA which is converted to catechol, therefore, the resistance is not activated (Glazebrook, 2005). The evaluations of the transgenic mutant 35S::nahG highlight the dependency of the SA pathway for triggering the resistance against biotrophs, mainly, by the greater DS for powdery mildew. This mutant presented an intermediate IP compared to the other mutants for this pathogen and a DI of $100 \%$, which characterizes 
an efficient infection of $O$. lycopersici on $35 \mathrm{~S}:$ :nahG. On the other hand, the double mutant dgt, $\mathrm{Nr}$ presented the lower DS for powdery mildew and the greater IP. For this mutant, the characteristics of low sensitivity to auxin and low sensitivity to ethylene are added. Studies indicate that auxin interacts in an antagonistic way with SA, suggesting that high concentrations of this hormone promote greater susceptibility to biotrophic pathogens (Robert-Seilaniantz et al., 2011). Ethylene, in contrast, presents synergism with jasmonic acid (JA) and the responses mediated by these two hormones act predominantly against necrotrophic organisms, wherein these signaling pathways are well-known and characterized regarding the antagonism with SA (Thaler et al., 2012).

The pathogen $B$. cinerea presents a parasitism of the necrotrophic type, acting on the host with cell wall degradation enzymes, toxins and other low weight molecular compounds, as a strategy of attack (Laluk \& Mengiste, 2010). In this case, the resistance triggered is controlled by the JA and ET pathways, and requires a wide range of genes to promote plant protection (Laluk \& Mengiste, 2010). When the hormone mutants were compared for the pathogen B. cinerea, the mutants Never ripe $(\mathrm{Nr})$ and dgt, $\mathrm{Nr}$ presented the greater FLS and $r$, respectively, indicating greater susceptibility to this necrotrophic pathogen. The Nr mutation compromises ET synthesis, making plants insensible to this hormone, whereas the double mutant dgt, $\mathrm{Nr}$, besides the reduction of ET production, also presents low sensibility to auxin. Thus, the low sensibility to auxin favors the SA signaling pathway, as an antagonist to the signaling promoted by JA, favoring the infection by necrotrophic pathogens, since besides this relationship, there is also a low

Table 1: Incubation period (IP) of gray mold and late blight, and latent period (LP) of powdery mildew on leaves of hormone mutant tomato plants cultivar Micro-Tom. ESALQ/USP, Piracicaba/SP, 2015

\begin{tabular}{llll}
\hline \multirow{2}{*}{ Mutant } & \multicolumn{1}{l}{ IP/LP(hours) } \\
\cline { 2 - 4 } & Gray mold & Late blight & Powdery mildew \\
\hline Micro-Tom & $52.00 \pm 2.00^{\mathrm{NS}}$ & $59.00 \pm 12.43^{\mathrm{NS}}$ & $208.00 \pm 13.38 \mathrm{ab}^{\underline{\prime}}$ \\
diageotropica & $32.00 \pm 14.83$ & $39.00 \pm 14.09$ & $192.00 \pm 6.57 \mathrm{~b}^{\prime}$ \\
Never ripe & $52.00 \pm 5.51$ & $55.00 \pm 7.00$ & $214.00 \pm 10.46 \mathrm{ab}$ \\
epinastic & $45.60 \pm 2.40$ & $35.00 \pm 7.16$ & $194.40 \pm 4.48 \mathrm{ab}$ \\
procera & $38.00 \pm 12.83$ & $46.00 \pm 11.86$ & $210.00 \pm 12.48 \mathrm{ab}$ \\
curl3 & $54.00 \pm 0.02$ & $50.00 \pm 2.52$ & $195.00 \pm 7.54 \mathrm{ab}$ \\
35S::nahG & $44.00 \pm 9.25$ & $70.00 \pm 24.42$ & $200.00 \pm 8.00 \mathrm{ab}$ \\
notabilis & $56.00 \pm 11.13$ & $52.00 \pm 5.51$ & $232.80 \pm 4.80 \mathrm{a}$ \\
dgt, pro & $58.00 \pm 10.00$ & $31.50 \pm 10.78$ & $204.00 \pm 10.73 \mathrm{ab}$ \\
dgt, Nr & $49.00 \pm 3.60$ & $46.00 \pm 2.00$ & $232.00 \pm 5.93 \mathrm{a}$ \\
dgt, epi & $54.00 \pm 6.00$ & $44.00 \pm 2.52$ & $196.00 \pm 11.02 \mathrm{ab}$ \\
\hline
\end{tabular}

${ }_{1}^{1}$ Means (of six measurements \pm standard error) followed by the same letter in the column do not differ between each other by the Tukey Test $(\mathrm{p} \leq 0.05)$. Ns Not significant by the F Test $(\mathrm{p} \leq 0.05)$.

Table 2: Disease incidence (DI) caused by Botrytis cinerea (gray mold - five days after inoculation), Phytophthora infestans (late blight - five days after inoculation) and Oidium lycopersici (powdery mildew - 15 days after inoculation) on leaves of hormone mutant tomato plants cultivar Micro-Tom. ESALQ/USP, Piracicaba/SP

\begin{tabular}{|c|c|c|c|}
\hline \multirow{2}{*}{ Mutant } & \multicolumn{3}{|l|}{ DI $(\%)$} \\
\hline & Gray mold & Late blight & Powdery mildew \\
\hline Micro-Tom & $100.00 \pm 0.00 \mathrm{a}^{1 /}$ & $100.00 \pm 0.00 \mathrm{a}$ & $100.00 \pm 0.00 \mathrm{a}$ \\
\hline diageotropica & $50.00 \pm 0.57 \mathrm{c}$ & $66.67 \pm 0.58 \mathrm{~d}$ & $83.33 \pm 0.70 \mathrm{~b}$ \\
\hline Never ripe & $100.00 \pm 0.00 \mathrm{a}$ & $100.00 \pm 0.00 \mathrm{a}$ & $100.00 \pm 0.00 \mathrm{a}$ \\
\hline epinastic & $100.00 \pm 0.00 \mathrm{a}$ & $83.33 \pm 0.59 b$ & $100.00 \pm 0.00 \mathrm{a}$ \\
\hline procera & $50.00 \pm 0.56 \mathrm{c}$ & $83.33 \pm 0.56 \mathrm{~b}$ & $83.33 \pm 0.70 \mathrm{~b}$ \\
\hline curl3 & $25.00 \pm 0.57 \mathrm{~d}$ & $100.00 \pm 0.00 \mathrm{a}$ & $80.00 \pm 0.58 \mathrm{c}$ \\
\hline 35S::nahG & $83.33 \pm 0.58 b$ & $50.00 \pm 0.58 \mathrm{e}$ & $100.00 \pm 0.00 \mathrm{a}$ \\
\hline notabilis & $50.00 \pm 0.57 \mathrm{c}$ & $100.00 \pm 0.00 \mathrm{a}$ & $83.33 \pm 0.72 b$ \\
\hline dgt, pro & $50.00 \pm 0.59 \mathrm{c}$ & $75.00 \pm 0.58 \mathrm{c}$ & $83.33 \pm 0.69 b$ \\
\hline dgt, $\mathrm{Nr}$ & $100.00 \pm 0.00 \mathrm{a}$ & $100.00 \pm 0.00 \mathrm{a}$ & $100.00 \pm 0.00 \mathrm{a}$ \\
\hline dgt, epi & $50.00 \pm 0.57 \mathrm{c}$ & $100.00 \pm 0.00 \mathrm{a}$ & $100.00 \pm 0.00 \mathrm{a}$ \\
\hline
\end{tabular}

${ }_{1}^{1}$ Means (of six measurements \pm standard error) followed by the same letter in the column do not differ between each other by the Tukey Test $(\mathrm{p} \leq 0.05)$. 
sensitivity to ET, which acts together with JA. Still, the mutant curl3, which presents low sensitivity to brassinosteroids (BR), presented low values for FLS and $r$. Studies indicate a negative interaction of BR with JA, thus, decreasing the sensitivity to BRs in the curl3 mutant may have favored the responses mediated by JA, with the reallocation of plant growth resources for defense responses (Campos \& Peres, 2012), and delaying the development of $B$. cinerea on leaf tissues.

As a characteristic of hemi-biotrophic organisms, $P$. infestans exhibits two different phases of pathogenesis, initially acting as biotrophs, suppressing programmed cell death with the absence of symptoms, and posteriorly acting as necrotrophs, being highly destructive and expressing disease symptoms (Lee \& Rose, 2010). Curl3 presents low sensitivity to BR, suggesting a lower interference on the JA signaling pathway which, in this case, may be acting antagonistically to the signaling triggered by the SA against $P$. infestans. On the other hand, mutants diageotropica, Never ripe and dgt, $\mathrm{Nr}$ were the most resistant to $P$. infestans. The greater resistance to late blight in the mutant dgt, low sensitivity to auxin, and $\mathrm{Nr}$, low sensitivity to ET that acts synergistically with JA, which in turn is antagonistic to SA, may have favored the signaling mediated by SA, important for resistance to hemi-biotrophs such as P. infestans (Bari \& Jones, 2009). The epi mutant presents, as a result of the mutation, ET overproduction which may have accelerated leaf senescence and predisposed plant tissues to the development of diseases caused by necrotrophic pathogens (Van Loon et al, 2006), possibly disfavored $P$. infestans since biotrophic and hemi-biotrophic parasitism rely on living tissues for establishment.

The interactions among hormonal signaling pathways against the attack of microorganisms act as important

Table 3: Final lesion size (FLS) at 216 hours after inoculation and lesion growth rate $(r)$ of gray mold on leaves of hormone mutant tomato plants cultivar Micro-Tom. ESALQ/USP, Piracicaba/SP, 2015

\begin{tabular}{lll}
\hline Mutant & FLS $(\mathbf{m m})$ & $\boldsymbol{r}$ \\
\hline Micro-Tom & $4.84 \pm 0.47 \mathrm{ab}^{-1}$ & $0.14 \pm 0.01 \mathrm{a}^{-1}$ \\
diageotropica & $1.85 \pm 0.85 \mathrm{ab}$ & $0.05 \pm 0.02 \mathrm{ab}$ \\
Never ripe & $5.74 \pm 0.93 \mathrm{a}$ & $0.15 \pm 0.01 \mathrm{a}$ \\
epinastic & $5.04 \pm 0.46 \mathrm{ab}$ & $0.12 \pm 0.01 \mathrm{ab}$ \\
procera & $4.31 \pm 1.80 \mathrm{ab}$ & $0.10 \pm 0.03 \mathrm{ab}$ \\
curl3 & $0.68 \pm 0.68 \mathrm{~b}$ & $0.02 \pm 0.02 \mathrm{~b}$ \\
35S::nahG & $4.18 \pm 0.88 \mathrm{ab}$ & $0.13 \pm 0.02 \mathrm{ab}$ \\
notabilis & $1.91 \pm 0.90 \mathrm{ab}$ & $0.06 \pm 0.02 \mathrm{ab}$ \\
dgt, pro & $2.15 \pm 1.04 \mathrm{ab}$ & $0.07 \pm 0.03 \mathrm{ab}$ \\
dgt, Nr & $4.82 \pm 0.68 \mathrm{ab}$ & $0.16 \pm 0.01 \mathrm{a}$ \\
dgt, epi & $2.13 \pm 0.95 \mathrm{ab}$ & $0.06 \pm 0.02 \mathrm{ab}$
\end{tabular}

${ }^{1}$ Means (of six measurements \pm standard error) followed by the same letter in the column do not differ between each other by the Tukey Test $(\mathrm{p} \leq 0.05)$.

Table 4: Disease severity (SD) caused by Phytophthora infestans (late blight - nine days after inoculation) and by Oidium lycopersici (powdery mildew - 22 days after inoculation) on leaves of hormone mutant tomato plants cultivar Micro-Tom. ESALQ/USP, Piracicaba/SP, 2015

\begin{tabular}{lcc}
\hline \multirow{2}{*}{ Mutant } & \multicolumn{2}{c}{ SD (\%) } \\
\cline { 2 - 3 } & \multicolumn{1}{c}{ Late blight } & Powdery mildew \\
\hline Micro-Tom & $30.66 \pm 14.74 \mathrm{abcd}^{1 /}$ & $31.92 \pm 9.97 \mathrm{ab}$ \\
diageotropica & $5.00 \pm 2.28 \mathrm{~d}$ & $31.72 \pm 9.85 \mathrm{ab}$ \\
Never ripe & $6.00 \pm 1.89 \mathrm{~cd}$ & $9.21 \pm 3.82 \mathrm{ab}$ \\
epinastic & $13.16 \pm 5.77 \mathrm{bcd}$ & $19.17 \pm 6.01 \mathrm{ab}$ \\
procera & $51.83 \pm 5.77 \mathrm{ab}$ & $23.02 \pm 9.77 \mathrm{ab}$ \\
curl3 & $71.33 \pm 3.58 \mathrm{a}$ & $10.36 \pm 5.21 \mathrm{ab}$ \\
35S::nahG & $50.50 \pm 14.41 \mathrm{abc}$ & $44.22 \pm 11.17 \mathrm{a}$ \\
notabilis & $23.33 \pm 3.71 \mathrm{bcd}$ & $14.76 \pm 7.07 \mathrm{ab}$ \\
dgt, pro & $25.25 \pm 17.48 \mathrm{bcd}$ & $24.87 \pm 8.73 \mathrm{ab}$ \\
dgt, Nr & $15.50 \pm 9.08 \mathrm{bcd}$ & $4.18 \pm 0.43 \mathrm{~b}$ \\
dgt, epi & $55.50 \pm 9.98 \mathrm{ab}$ & $26.50 \pm 6.45 \mathrm{ab}$ \\
\hline
\end{tabular}

1/Means (of six measurements \pm standard error) followed by the same letter in the column do not differ between each other by the Tukey Test $(\mathrm{p} \leq 0.05)$.

Rev. Ceres, Viçosa, v. 68, n.3, p. 212-218, may/jun, 2021 
mechanisms of regulation of defense responses accordingly to the type of pathogen, since each invader explores different resources, in a specialized manner, for the establishment of parasitic relationships with the host (Pieterse et al., 2009). According to Alonso \& Ecker (2001), there are three different levels of hormone interaction. The level of hormonal response, where hormones may interact regulating a common set of target genes. The level of signal transcription, in which a hormone, besides acting on its own signaling pathway, also interferes on the signaling pathway of another hormone. And the level of biosynthesis, where the hormone production rate changes in response to another hormone.

The BR hormone, which possess multiple effects in a variety of plant growth stages, interferes on the total balance and in the concentration of other plant hormones, acting independently of the biosynthesis of SA, but interacting with other phytohormones such as ABA, ET and JA (Bari \& Jones, 2009; Campos \& Peres, 2012), promoting resistance or susceptibility to different pathogens (Korner et al.; 2013). According to Campos et al (2009), the interactions of BRs with JA occur in an antagonistic way, which indicates that the mutation present in curl3 does not regulate the JA mediated pathway. Since the signaling by JA is active, the SA pathway is low due to the antagonism between both, favoring infections caused by biotrophic and hemi-biotrophic organisms, and impairing necrotrophs, as can be observed in the inoculations with $B$. cinerea. The moderate tolerance to $O$. lycopersici may be explained by the augmented levels of ET, due to the synergism with JA, accelerating leaf senescence, possibly impairing the development of biotrophic organisms, that require living tissues (Van Loon et al., 2006). Studies with the exogenous application of BR on potato plants demonstrated the resistance to $P$. infestans infection and this resistance was associated with the increase in the levels of ABA and ET. These results suggest that there is an interaction between BR and other hormonal signals on the mediation of plant defense responses (Bari \& Jones, 2009).

The SA is a hormone knowingly related to the defense against biotrophic pathogens, and the transgenic 35S::nahG, which presents a deficiency in the accumulation of SA, presented different results among the pathogens used. When inoculated with $O$. lycopersici, the powdery mildew occurred on all plants, as well as DS indexes were greater, indicating a higher susceptibility against this pathogen, while on plants inoculated with $B$. cinerea the disease did not occur on all plants and the FLS and $r$ presented intermediate values. However, in the inoculations with $P$. infestans, 35S::nahG presented the lower DI for late blight, which was not observed during disease development, that presented high severity, demonstrating that the deficiency of SA is favorable for processes that occur after infection.

Other hormonal relationship that differentiated depending on the type of parasitism occurred through the mutant notabilis, which demonstrated greater susceptibility to $P$. infestans and greater resistance to $B$. cinerea. The abscisic acid (ABA), which is deficient in this mutant, play an important role throughout plant life cycle, being the main phytohormone involved in the responses to abiotic stresses, regulating, for example, the stomatal closure (Raghavendra et al., 2010), this may favor the infection by some pathogens, such as P. infestans. Furthermore, the resistance or susceptibility mediated by $\mathrm{ABA}$ is oftentimes thought to be a consequence of the interference on defense hormones, such as JA, SA, or ET (Xu et al., 2013).

In summary, the gray mold disease, caused by $B$. cinerea, was impaired by the deficiencies of the hormones $\mathrm{BR}$ and $\mathrm{ABA}$, that present antagonism with the pathways of JA and ET, respectively (Campos \& Peres, 2012), known to be related to the defenses against necrotrophs. In contrast, late blight, caused by P. infestans, benefited from the deficiency of the hormone BR, as well as the deficiency of SA, after infection, reinforcing the importance of the signaling pathway mediated by SA against hemi-biotrophs and biotrophs (Bari \& Jones, 2009), this last represented by $O$. lycopersici, that causes the powdery mildew, which in turn, also benefited by the deficiency of SA.

\section{CONCLUSIONS}

Brassinosteroids are complex hormones and the low sensitivity confers greater susceptibility to Phytophthora infestans and high resistance to Botrytis cinerea.

Auxin is an important hormone related to microorganism pathogenicity, since its deficiency in tomato mutants conferred high resistance to diseases caused by Oidium lycopersici, Phytophthora infestans and Botrytis cinerea.

\section{ACKNOWLEDGEMENTS, FINANCIAL SUPPORT AND FULL DISCLOSURE}

This study was financed in part by the Coordenação de Aperfeiçoamento de Pessoal de Nível Superior - Brasil (CAPES) - Finace Code 001.

\section{CONFLICT OF INTERESTS}

There is no conflict of interest in the conduct and publication of this work.

\section{REFERENCES}

Alonso MJ \& Ecker JR (2001) The ethylene pathway: a paradigm for plant hormone signaling and interaction. Sci STKE, 70:0110 .

Rev. Ceres, Viçosa, v. 68, n.3, p. 212-218, may/jun, 2021 
Bari R \& Jones JDG (2009) Role of plant hormones in plant defence responses. Plant Molecular Biology, 69:473-488.

Campos ML \& Peres LEP (2012) Brassinosteroids as mediators of plant biotic stress responses. In: Pereira-Netto AB (Ed.) Brassinosteroids: pratical applications in agriculture and human health. Sharjah, Bentham Science Publishers. p.35-43.

Campos ML, Almeida M, Rossi ML, Martinelli AP, Litholdo CG, Figueira A, Rampelotti-Ferreira FT, Vendramim JD, Benedito VA \& Peres LEP (2009) Brassinosteroids Interact negatively with jasmonates in the formation of anti-herbivory traits in tomato. Journal of Experimental Botany, 60:4347-4361.

Corrêa FM, Bueno Filho JSS \& Carmo MGF (2009) Comparison of three diagrammatic Keys for the quantification of late blight in tomato leaves. Plant Pathology, 58:1128-1133.

Dallagnol LJ \& Araujo Filho JV (2018) Uma visão geral da resistência genética da planta a microrganismos. In: Dallagnol LJ (Ed.) Resistência genética de plantas a patógenos. Pelotas, UFPel. p.14-64.

Debona D \& Rodrigues FA (2018) Alterações bioquímicas e estruturais em plantas induzidas após a detecção do patógeno. In: Dallagnol LJ (Ed.) Resistência genética de plantas a patógenos. Pelotas, UFPel. p.150-193.

Freeman BC \& Beattie GA (2008) An overview of plant defenses against pathogens and herbivores. Plant Pathology and Microbiology Publications, 94:01-14.

Glazebrook J (2005) Contrasting mechanisms of defense against biotrophic and necrotrophic pathogens. Phytopathology, 43:205-227.

Inácio MC, Silva ES, Souza ME, Ono EO \& Rodrigues JD (2011) Secondary messengers related to the action of plant hormones. Revista Brasileira de Agrociência, 17:438-446.

Jones JDG \& Dangl JL (2006) The plant immune system. Nature, 444:323-329.

Kazan K \& Lyons R (2014) Intervention of phytohormone pathways by pathogen effectors. Plant Cell, 26:2285-2309.

Korner CJ, Klauser D, Niehl A, Domínguez-Ferreras A, Chinchilla D, Boller T, Heinlein M \& Hann DR (2013) The immunity regulator BAK1 contributes to resistance against diverse RNA viruses. Molecular Plant-Microbe Interactions, 26:1271-1280.

Laluk K \& Mengiste T (2010) Necrotroph attacks on plants: wanton destruction or covert extortion? American Society of Plant Biologists, 10:01-34.

Lee SJ \& Rose JKC (2010) Mediation of the transition from biotrophy to necrotrophy in hemibiotrophic plant pathogens by secreted effector proteins. Plant Signaling \& Behavior, 5:769772 .
Nick C, Laurindo BS, Almeida VC, Freitas RD, Aguilera JG, Silva ECF, Cruz CD \& Silva DJH (2013) Simultaneous selection for fruit quality and resistence to late blight in tomato progenies. Pesquisa Agropecuária Brasileira, 48:59-65.

Pascholati SF, Leite B, Stangarlin JR \& Cia P (2008) Interação planta-patógeno: fisiologia, bioquímica e biologia molecular. Piracicaba, FEALQ. 627p.

Pereira BLS (2015) Estudo da influência da cobertura do solo nas condições ambientais, na produção e na ocorrência de Botrytis cinerea numa cultura de tomate em estufa. Dissertação de Mestrado. Universidade de Évora, Évora. 80p.

Pieterse CMJ, Leon-Reyes A, Van der Ent S \& Van Wees SCM (2009) Networking by small-molecule hormones in plant immunity. Nature Chemical Biology, 5:308-316.

Pieterse CMJ \& Dicke M (2007) Plant interactions with microbes and insects: from molecular mechanisms to ecology. Trends in Plant Science, 12:564-569.

Raghavendra AS, Gonugunta VK, Christmann A \& Grill E (2010) ABA perception and signalling. Trends in Plant Science, 15:395401 .

Robert-Seilaniantz A, Grant M \& Jones JDG (2011) Hormone crosstalk in plant disease and defense: more than just jasmonatesalicylate antagonismo. Annual Review of Phytopathology, 49:317-343.

Thaler JS, Humphrey PT \& Whiteman NK (2012) Evolution of jasmonate and salicylate signal crosstalk. Trends in Plant Science, 17:260-270.

Torres RV, García JM, Pozo MJ \& López-Ráez JÁ (2014) Do strigolactones contribute to plant defence. Plant Pathology, 15:211-216

Uma B, Rani TS \& Podile AR (2011) Warriors at the gate that never sleep: Non-host resistance in plants. Journal of Plant Physiology, 168:2141-2152.

Van Loon LC, Geraats BPJ \& Linthorst HJM (2006) Ethylene as a modulator of disease resistance in plants. Trends in Plant Science, 11:184-191.

Vleeshouwers VGAA \& Oliver RP (2014) Effectors as tools in disease resistance breeding against biotrophic, hemibiotrophic, and necrotrophic plant pathogens. Molecular Plant-Microbe Interactions, 27:196-206.

Xu ZY, Kim DH \& Hwang I (2013) ABA homeostasis and signaling involving multiple subcellular compartments and multiple receptors. Plant Cell, 32:807-813. 